\title{
Equality as a Threshold Conception: Challenging future manager's perceptions
}

\author{
Abstract \\ Purpose: The purpose of this paper is to examine the potential to develop a shared \\ understanding of systemic discrimination and the complexity of equality and an appreciation \\ for the range of interventions designed to redress inequality within the context of business \\ school curricula.
}

Design/methodology/approach: Qualitative material was gathered over a four-year period through written reflections of student interpretations of equality. Participants were enrolled in a human resource management course critically examining systemic gender discrimination, women's organisational experiences, gendered employment outcomes, and the range of interventions designed to redress gendered employment outcomes. Threshold concepts framed the analysis of participant reflections.

Findings: The paper shows that while the participants developed a shared understanding of systemic gender discrimination, their interpretations of equality and appreciation for the range of interventions available to redress inequality differed. These differences were shaped by 1) the extent to which participants integrated their understanding of systemic discrimination with their interpretations of equality and 2) the extent to which the interventions to inequality transformed, upheld or challenged participant agendic self-identity and world view.

Practical implications: The differences in interpretations have implications for the way educators introduce discussions of equality within the business school classroom.

Originality: The paper demonstrates that developing a shared understanding of systemic discrimination does not always lead to developing a shared understanding of the complexity of equality or appreciation for the many forms of interventions available.

Keywords: systemic discrimination, formal and substantive equality, threshold concept Paper Type: Research Paper

\section{Introduction}

Concern for equality in employment for all regardless of demographic features such as gender, age, ethnicity, and religion has a long history. Women have been identified as a specific group who experience persistent systemic discrimination in employment (National Council of Women New Zealand, NCWNZ, 2015). Over the past 40 years, a raft of United Nations (UN), government, and organisational initiatives have been designed to improve women's access to, and mobility within, employment (Terjesen and Sealy, 2016). New Zealand, as a small advanced economy, has a history that includes being the first to legislate female suffrage. So too, New Zealand has signalled a commitment to equal employment outcomes for women by 
ratifying a number of International Labour Organization (ILO) Conventions and the UN Convention on the Elimination of all Forms of Discrimination Against Women (CEDAW) (Ministry of Business, Innovation, and Employment, 2015). The CEDAW convention requires governments to redress gender discrimination by establishing both formal and substantive equality measures (Facio and Morgan, 2009). Formal equality requires developing a legal framework ensuring women have the same rights to equality as men, and substantive equality requires developing political, economic, social and cultural conditions to enable women to enjoy these formal rights.

In line with this international commitment, successive New Zealand governments have developed a minimum anti-discrimination legal framework to establish formal equality between men and women (Ryan, Ravenswood and Pringle, 2014). In relation to employment, this legal framework includes rights to equal pay, the right not to be discriminated against on the grounds of sex, marital status, parental status, and pregnancy, the provision of paid parental leave and flexible work options, and the right to breastfeeding breaks. In addition, considerable work has examined socio-cultural and organisational processes that promote and prevent the achievement of equality in employment for women (Messing et al. 2000; Sharma and Sharma, 2012). Equality in employment within New Zealand has been examined at the intersection of multiple demographic features such as age, gender, disability, ethnicity, and migrant status (Ryan et al., 2014).

Despite this strong focus, gender inequality in New Zealand employment outcomes persists (NCWNZ, 2015). New Zealand women continue to experience horizontal segregation with $60 \%$ of the female workforce concentrated in healthcare and social assistance, wholesale and retail, education and training and other business services (Statistics New Zealand, 2016). Additionally, although women make up $46.7 \%$ of the paid workforce, they only account for $39.5 \%$ of fulltime workers, emphasising an overrepresentation in part-time employment. New Zealand women also experience vertical segregation, with an underrepresentation in senior leadership roles (Ministry for Women, 2016), and continue to experience a gender pay gap of 12.71\% (Pacheo et al., 2017). A number of factors impact New Zealand women's ability to fully participate in the workforce. For example, childcare as a proportion of income in New Zealand is the second highest in the OECD. These patterns are exacerbated for New Zealand women on the basis of ethnicity, dis/ability and migrant status (Ryan et al., 2014). Certainly, these patterns are not unique to New Zealand; rather, horizontal and vertical segregation and 
the gender pay gap are enduring features of international labour market outcomes (ILO, 2016; United Nations Women, 2015).

The National Council of Women of New Zealand (NCWNZ, 2015) define the persistence of gender inequality as a 'wicked' problem (p. 20). As a wicked problem, gender inequality is difficult to define and has multiple interpretations, and is shaped by complex and 'interdependent factors' which are deeply rooted in economic and social structures (p. 20). Given this persistence, the NCWNZ call for a new approach to gender equality that goes beyond traditional endeavours. Specifically, they suggest that to realise gender equality will require developing a shared understanding about what constitutes inequality, creating a genderpositive culture free from stereotypes and bias, dismantling structural inequalities, monitoring progress towards gender equality, and developing informed individual, government, business and community leaders who are committed to gender equality.

We agree with importance of developing a shared understanding about systemic discrimination and equality, and hold that business schools are in a unique position in this regard. Our view is mandated by Section 162 (4a) of the Education Act 1989 requiring New Zealand Universities to 'accept a role as critic and conscience of society'. A number of scholars have already examined university student pre-conceptions about equality and gender discrimination in employment (Fetterolf and Eagly, 2011; Finney, et al., 2014; Sipe et al., 2016). Many have concluded that students, and young women in particular, perceive that gender equality has been achieved. Moreover, Sipe et al. (2016) found that business school students considerably underestimate workplace gender discrimination and believe that such discrimination would not impact them personally. In harmony with NCWNZ, Sipe et al., conclude that it is 'necessary' to develop business school curriculum to both raise awareness about the pervasiveness of discrimination and to educate students about the interventions designed to redress gendered employment outcomes (p. 236).

Within the context of a human resource management (HRM) course, we strive to develop a shared understanding of gendered inequality, and in so doing, we hope to contribute to developing informed and committed future leaders. The course, which forms the context of this research, highlights systemic discrimination, critiques socio-cultural and organisational practices that reproduce gendered employment outcomes, and examines the complexity of equality interventions designed to redress workplace inequality. Elsewhere we show that it is possible to raise management student awareness about systematic discrimination (self- 
disclosing reference). In this article, we build on this prior work to consider whether it is similarly possible to develop deeper understandings of the complexity of equality within the context of business school curricular. Specifically, we base this research around the following question: How do management students, who have analysed systemic discrimination, interpret equality as an employment issue and make sense of and appreciate the interventions designed to redress gendered employment outcomes?

The paper is structured as follows. First, we contextualise this study by reviewing the New Zealand Government commitment to gender equality in employment through promoting equal employment opportunity (EEO), diversity management (DM) and inclusion, and then briefly critique the context and concept of equality. Next, we introduce equality as a threshold concept, and present the method used to collect and analyse student interpretations of equality. The findings reveal that although all participants understood systemic discrimination, they did not necessarily develop a sophisticated understanding of equality or fully appreciate the range of interventions designed to redress inequality. We discuss how these differences in interpretation and appreciation seemed to be influenced by: 1) the extent to which participants integrated their understanding of systemic discrimination with their interpretation of equality, and 2) the extent to which the interventions to inequality were experienced as transforming, upholding or challenging participant world view and agendic self-identity. We consider the implications of our findings for educators wishing to introduce discussions of equality into the business school classroom, and conclude that to develop sophisticated understandings of equality requires supporting students to integrate their understanding of systemic discrimination with employment inequalities. We now turn to a discussion of the New Zealand Government commitment to equality.

\section{New Zealand Government commitment: Promoting EEO and DM in the Workplace}

Debates surrounding the principles of equality and fairness and how equality and fairness might be achieved within employment are not new. In their review, Oswick and Noon (2014) track the chronological development and the discursive shifts distinguishing equality from diversity, and diversity from inclusion. They demonstrate that chronologically, EEO and AA predominated between the 1970s and the 1990s, and were frequently mandated by legislation. Discursively, EEO and AA were embedded with concerns for social justice and the need to redress unequal employment outcomes of specific target groups. By the 1990s, this legislative mandate, the narrow focus on sex, ethnicity, and age, and the focus on group-based 
comparisons at the expense of individual-level differences and intersectional discrimination were increasingly criticised (Knights and Omanovic, 2016).

Oswick and Noon suggest that as part of this critique, DM was offered as an alternative to EEO and AA. Discursively, DM is synonymous with the business case, emphasising profitability, the voluntary self-regulated efforts of organisations (Beck and Davis, 2005), and the management of deep-level individual difference (Knights and Omanovic, 2016). More recently, DM has been critiqued for deemphasising social justice, a narrow productivity focus, and for failing to integrate individual difference within business processes (Oswick and Noon, 2014; Pringle and Strachan, 2015).

Although New Zealand's anti-discrimination framework has been shaped by its unique context (Ryan et al., 2014), the concern for equality in employment mirrors many aspects of the chronological development internationally, as highlighted by Oswick and Noon (2014). For example, throughout the 1980s, there was a strong focus on developing EEO policies to redress the historic disadvantage in the labour market experienced by women, Maori, ethnic minorities and people with disabilities (Mintrom and True, 2004). This focus was mandated in legislation for government employers while private sector employees were encouraged to voluntarily do the same (Ryan, et al., 2014), a situation that remains in place today. Similarly, throughout the 1990s in New Zealand, EEO was being constructed as a 'management practice [to] minimize the potential for employers to be found guilty of discrimination' (Mintrom and True, 2004, p. 27). Likewise, during the 1990s, there was a shift from the social justice imperatives embedded in EEO toward an embracement of the business case embedded in DM and a greater concern for addressing discrimination experienced at the individual rather than group-level. This shift in focus from historic disadvantage experienced between groups to discrimination experienced at the individual level coincided with the implementation of neo-liberalism with the New Zealand political-economy (Humphries and Grice, 1995). Along with deregulating many areas of the economy, including the labour market, neo-liberal principles of meritocracy and individual freedom, choice and agency have been used to frame the neo-liberal subject (Davies, McGregor, Pringle, and Giddens, 2017).

McRobbie (2004) argues that these same neo-liberal principles are embedded in the post-feminist discourse. Thus, rather than view the self as a member of a disadvantaged group, women are encouraged to frame themselves as agendic and empowered (Gill and Scharff, 2011). The individual woman is charged with the responsibility to make meaningful life 
choices, to acquire marketable skills, manage and amend the self to fit current workplace structures, and accept inequality as an outcome of personal choice (Phipps, 2014). Structural inequality and the embedded power-relationships between groups that support disadvantage have therefore become obscured behind a rhetoric of individual freedom and responsibility (Ryan et al., 2014). Thus, alongside the chronological and discursive development of these interventions, there has been an ongoing scholarly debate about the relevance of equality as a concept, particularly within the context of neo-liberalism.

\section{Critiquing the Concept and Context of Equality}

While many Governments, including our own, have established formal equality measures to facilitate women's access to, and advancement within, employment, they have been less willing to introduce policies that challenge the 'structural interaction between paid and unpaid work' and women's subordination in society and employment (Elson, 2009, p. 44; Annesley et al, 2015). However, because of this structural subordination, women come to, and compete within the labour market on an unequal footing (Elson, 2009). Even when organisations develop worklife balance policies (McPherson, 2008; Parker et al. 2012), taking advantage of them negatively affects women’s career progression (Bacik and Drew, 2006).

Within this context, equality principles have had a limited effect on achieving substantive equal employment outcomes for women (McDonald, 2014). Moreover, many initiatives typically assist women to engage in existing structures, without addressing the power differentials and mechanisms that 'sustain and reproduce both privilege and marginalisation' (Arat, 2015, p. 685); a situation that is pronounced in the context of neo-liberal marketization. These concerns have led to a theoretical shift in the conception of equality that takes into account the historic gendering of socio-cultural and economic privileging and patriarchal relationships (McDonald, 2014). Despite these deeper analyses, there remains little agreement about, or conclusive evidence to support what might constitute effective and enduring equality interventions (NCWNZ, 2015). However, we suggest that realising equality will require a sophisticated understanding of both the complexity of equality and of the interventions designed to redress inequality. It is within this complex environment that we conceptualise equality as a threshold concept. 


\section{Equality as a Threshold Conception}

Equality and the interventions designed to redress inequality can be viewed as threshold conceptions. Meyer and Land (2003) suggest a 'threshold concept can be considered as akin to a portal, opening up a new and previously inaccessible way of thinking about something ... without which the learner cannot progress' (p. 1). They characterise threshold concepts as being transformative, integrative, bounded, troublesome and irreversible. Once comprehended, threshold concepts can transform the way a learner thinks about a discipline, how they experience or comprehend particular aspects of the discipline, and even transform the learner's worldview. Threshold concepts are integrative because they reveal interrelationships between course material and abstract ideas that were previously hidden from the learner's conceptual view. The integrative aspect of grasping the way concepts 'interact in a process of increasing complexity' has led to a distinction between threshold concepts and threshold conceptions (Wright and Gilmore, 2012, p. 615).

Developing an appreciation for the complexity of equality may act as a portal, leading to the transformation of the learner's prior ideas and worldview about women in society and employment, and the ways that gender discrimination might be redressed. The complexity of equality is certainly integrative as it exposes structural relationships between women's unequal employment outcomes and gender discrimination, paid and unpaid work, biological difference, gendered socio-cultural, legal and organisational processes and practices, and patriarchal relationships. This integrative and transformational potential is indeed fraught with troublesome knowledge that may challenge prior world view and personal identity and as such, learners' may experience a 'repositioning of the self' (Meyer and Land, 2005, 374).

Land et al. (2005) describe the learning process as moving from a pre-liminal space of existing understandings, to a liminal space where learners may grapple with the threshold concept, and then to a post-liminal space of comprehension. They stress that learning a threshold concept is not necessarily a linear process; students may osculate between the preliminal, liminal, and post liminal spaces. Some may oscillate between their 'less sophisticated understandings' and the complexity of the threshold concept (p. 55), but remain in the preliminal space because they hold on to initial understandings. Those who move to the postliminal space often let go of previously held assumptions, ideas or tacit knowledge, and are thus likely to experience a change in world view. 
The transformational potential means that encountering a threshold concept may be experienced as an emotional journey fraught with tension, self-doubt and discomfort as students grapple with complex knowledge and develop deeper insights that challenge previously held ideas (Hawkins and Edwards, 2015). However, a number of teaching techniques have been observed to support learners to comprehend threshold concepts and to move through pre-liminal, liminal, and post-liminal spaces. In the first instance, Land et al., (2005) argue that helping learners to comprehend threshold concepts requires carefully considering and reviewing the sequence of course content, 'the processes used to ready students to recognise and internalise threshold concepts, [and], the ways in which learners and teachers recognise the threshold concepts are internalised' (p. 57). Some of the processes used to prepare students include developing active, social, and creative learning environments (Bradley, et al., 2015) and posing reflexive questions, and designing participative group exercises, discussions and debates (Hawkins and Edwards, 2015). Enabling learners to draw on personal experience to help make sense of course content, introducing multiple theoretical lenses, and providing support materials has also proved effective (Hibbert and Cunliffe, 2015; Bradley et al, 2005; Wright and Gilmore, 2012; Land et al, 2005).

We use many of these suggested techniques within our teaching practice. The course that forms the basis of this research is taught once per year, with each cohort averaging 20 students; the vast majority of whom are women specialising in HRM. Our teaching philosophy is informed by critical feminist pedagogy with the aim of developing student understanding of the ways patriarchy shapes and constrains women’s daily lives (Stoke, 2007). We pay careful attention to the content and sequencing of topics in course design, introduce multiple theoretical lenses to analyse course material, provide supportive readings, and embed current event case-studies within lectures. Lectures are based around posing reflexive questions, group discussions, and dialogue. Learning is also supported by a reflexive journaling assignment which has been found to be particularly useful for helping students comprehend threshold concepts (Hibbert and Cunliffe, 2015). Reflexive journals enable learners to consider difficult topics, make sense of personal experience in relation to the socio-cultural realm and political economy, and question their own assumptions, practices, and worldview. Reflexive journals are also considered a record of student learning and as providing empirical evidence of their learning process (O’Connell and Dyment, 2011). Because of this, we have used the reflective journal assignment as the empirical data to explore how students who have examined structural inequality interpret equality and make sense of the interventions designed to redress gendered 
employment outcomes. That is, the reflexive journals may highlight whether the learner has remained in the pre-liminal space, become stuck in the liminal space, or comprehended the threshold concept and moved to the post-liminal space.

\section{Method}

The data used in the current study is drawn from a larger research project intended to both examine student experiences of participating in this course and as a way to review the course design and teaching practice. Due to the small class size, we chose to gather data over a four year period to gain critical mass to allow for deep thematic analysis. The data comprised of a formal written assignment requiring students to reflect on eight of the 12 lectures presented throughout the course. Each reflection had a limit of 500 words. Equality is introduced in week eight of a 12-week semester. The topics presented in the seven preceding weeks include the theoretical and social construction of gender, feminist theories, sexual harassment, and the gendered education and employment outcomes of New Zealand women (Statistics New Zealand, 2015). Hence, prior to the lecture on equality, students are aware that gender inequality in employment exists, and have been introduced to a critical feminist analysis of how these outcomes are produced and reproduced within socio-cultural practices, family arrangements, the political economy and the employment environment (McDonald, 2014).

In accordance with the Ethical Approval obtained for this research, participation was voluntary, and to avoid feelings of coercion, students were invited to submit their assignments as data at the end of semester and after all grades had been finalised. Sixty of the 86 students enrolled in the four year period submitted their assignments. An initial content analysis of these 60 assignments revealed that 38 participants reflected on the topic of equality, 35 of whom were women, and three men. Of the women, there were 23 New Zealand and 11 international students; whereas two of the men were New Zealanders and one was an international student. No other demographic data was collected from participants.

The analytical strategy involved independent deductive analysis performed by each researcher (Braun \& Clarke, 2006). This initial analysis resulted in the identification of five themes which addressed, in some way, the concept of equality. These themes included: 1) a comprehensive understanding of systemic discrimination, 2) interpreting equality as discrimination, 3) embracing equality as a means to ensure meritocracy, 4) embracing equality as a means to achieve individual and business benefits, and 5) engaging in a structural critique 
of equality. The second stage of the analysis was informed by Land et al.'s (2005) conceptualisation of pre-liminal, liminal, and post-liminality, and involved considering the five themes in light of this framework. Specifically, we considered participants to be in the preliminal space if their existing assumptions, tacit knowledge, or self-identity remained embedded in their reflections. Those in the liminal space demonstrated a partial or incomplete interpretation of equality, developed an appreciation for a limited range of equality interventions, and osculated between previous assumptions and deeper meanings. Participants who moved to the post-liminal space engaged in deep analysis of the complexity of equality, developed a sophisticated appreciation for the interventions available, and experienced a change in world view and/or a transformation in their self-identity. We now turn to the findings where we have used pseudonyms to protect participant identity.

\section{Findings}

As their starting point, all 38 participants developed sophisticated understandings of systemic discrimination and of gender inequality in employment and wider society. Amid their reflections deep connections were made, for example, between globalisation, consumerism and women's poverty, prior feminist activism and women's current access to higher education and employment, and gendered cultural practices in the home and women's restricted employment opportunities. While a sophisticated analysis of systemic gender discrimination could be discerned, the interpretations of equality and appreciation for the interventions differed. As we see below, five women rejected equality and the interventions designed to redress inequality and remained in the pre-liminal space, 17 participants, including the three men, developed partial understandings and remained in the liminal space, and 16 grasped the complexity of equality and moved to the post-liminal space.

\section{The Pre-liminal Space: Challenging Self-identity and Rejecting Equality}

The five women who remained in the pre-liminal space described CEDAW, governments, or organisational efforts to enhance women and girls position in society and employment as 'good', 'great', and 'fantastic'. However, while they understood the effects of systemic discrimination, they drew on their prior understandings in their interpretations of equality and in their appreciation for the interventions to address inequality. Equality was 
interpreted as applying identical treatment, and in general, they viewed differential treatment in recruitment, hiring, or promotional decisions as gender discrimination. This is illustrated by Mary, who perceived that 'managers should only employ those who are capable of doing the work and not discriminate against anyone’.

These five women especially rejected the idea of personally being treated differently based on their gender. Like Sipe et al., (2016), and despite learning about inequality, they perceived that gender discrimination would not impact them personally, nor restrict their access to or advancement within employment. Instead, reflecting Jolles' (2012) research, they drew on a neo-liberal rhetoric to frame themselves as capable and agentic individuals and incorporated past feminist gains into their interpretation of equality. Hence, they continued to believe that their future careers would be based on self-determination and personal ability. Indeed, they categorically stated they wanted to be judged according to their skills and not their gender. This is best captured by Sarah:

[I] recognise the fact that everything I have been able to achieve has not all been because of my own actions, but can be contributed a lot [of] opening of doors done by the millions of woman [before me]... I believe in the advancement of those [who] are qualified and able to perform well [and they should not be] barred due to ... gender [or] sexual orientation. But I do not believe in advancing women who are not qualified ... just for the sake of the empowerment of women, or other minorities. ... I don't want to be judged as incapable because of my gender, if I am incapable it is because I lack the skills or knowledge, which I can change. I do not want to get a job simply because I am a woman.

In summary, the complexity of equality, and especially in terms of differential treatment, challenged how these women perceived themselves. Their osculation between their sophisticated understandings of systemic discrimination and past feminist achievements and their less sophisticated position on equality enabled them to hold on to their agendic selfidentity. Rather than let go of their self-identity, they dismissed their new understanding of systemic discrimination and gendered employment outcomes by interpreting equality as discrimination, and by redefining systemic gendered employment outcomes as a consequence of an individual skill-gap. 
The 17 participants who remained in the liminal space embedded their prior assumptions, tacit knowledge and self-identity in to their interpretation of equality and appreciation for the interventions available. These participants similarly interpreted equality as applying identical treatment and constructed themselves as capable, agendic individuals. They also expressed their sense of 'security' 'relief' and 'encouragement' to learn that 'others' are 'addressing' discrimination on their behalf. However, they appreciated interventionist strategies as securing their individual rights to freedom from discrimination in employment and as upholding and supporting their agendic self-identity.

Some of these participants extended their analysis and appreciated that employment equality interventions can have a positive flow-on effect to women as a group. They reflected on women's increased qualification attainment and need to earn income to support themselves and their families. They viewed equality interventions as necessary to uphold human rights and to ensure that women have access to employment that reflects their talent, interest, and skills, and their need to earn a living. They appreciated the need for 'removing obstructions' in recruitment and hiring decisions, including changing job descriptions to 'truly reflect the requirements needed'. They particularly favoured measures that assured 'development opportunities' were based on merit and that appraisals reflected 'actual performance'.

Significantly, many of these 17 participants simultaneously advanced the business case for equality as embedded in the DM literature (Knights and Omanovic, 2016). Thus, interventions to remove gender bias from employment were appreciated as mechanisms to advance women's careers and improve business outcomes. Joanna captures this dual position when she reflects on organisational efforts to remove gendered barriers to employment:

[It is] encouraging to me as a women to know I will have others looking out for my rights as an individual. Not only do I benefit from this ... but businesses [also] benefit.

Equality was thus interpreted as making 'good business sense' as it widens the recruitment pool and enables the most suitable candidates to advance to managerial positions. Additionally, the participants perceived that by recruiting and promoting on the 'basis of merit', employees could fully engage their 'talents' and 'capacities'. As a result, they thought 
employees would be more 'enthusiastic' and 'loyal' and 'businesses would become more efficient and profitable'. These views are encapsulated in Tracey’s reflection:

If someone is motivated by their organization, he or she will try their best at work. Generally speaking, employees always judge their treatment as a scale of their importance to the organization. Therefore, treating employees well will inspire their enthusiasm, because of this, employees will work harder than before, and the organization will enjoy increased productivity and get more profit.

While still advancing the business case, some osculated back to pre-liminal gendered understandings of skill and talent. In these instances, the participants viewed that by ensuring merit-based recruitment and promotional decisions, businesses could 'profit' from including and realising women's 'unique skills and talents' and that women's influence would provide a 'balance to business decision making'. Suzanne particularly illustrates this view:

Because of sex differences, women are good at some things compared to men, such as communication, understanding, and being approachable. In my opinion, these are special skills of women, as females. Taking advantage of women's specialist skills can balance out, and make up for, the short fall of men... Women can use their advantage to make something more effective... and therefore ... [help] organizations improve productivity.

Some concluded that addressing equality in the employment space would lead to a more 'harmonious' society. These reflections resonated with Staines (1980) theorisation, whereby the feelings of loyalty and enthusiasm generated from 'skill recognition' and 'talent utilisation' were perceived to positively spill-over to the family domain. Others felt that equality measures would reduce the gender-pay gap and as a result, have a positive financial effect on women's family.

Two of the men recognised government and organisational interventions as having a positive effect on increasing the number of women in employment. These men made distinctions between workplace discrimination and women's choice to remove themselves from employment to become 'housewives'. However, as demonstrated by Aaron, they did not take in to account the ways that systemic discrimination constrain women's choices: 
There are more professional women who are choosing to leave work and become housewives. Some argue that this retrogression will damage the status of women. However, I think there is a distinction between disparity from work and a willingness to be a housewife. Disparity at work represents discrimination and lowers the status of women; the latter is a choice made by women.

In summary, these participants did not integrate their understanding of systemic discrimination with their knowledge of unequal employment outcomes. Instead, their analysis focused on securing women's access to current employment structures. This was particularly evident in the way identical treatment and meritocracy was foregrounded in both their interpretation of equality and in their appreciation for interventions that remove organisationalbased obstacles to skilled and talented women. Significantly, their interpretation of equality and their appreciation for a limited range of interventions upheld their agendic self-identity. Thus, while holding positive views, they remained in the liminal space.

\section{The Post-liminal Space: Challenging Structures and Transforming Self-identities}

The remaining 16 participants integrated their understanding of systemic discrimination with their knowledge of gendered employment outcomes. They embedded the gendering of family arrangements, employment practices, and the political-economy within their complex interpretations of equality. They appreciated that to realise substantive equality would require a range of interventions that go well beyond the employment environment. This deeper structural critique led to a letting go of previously held assumptions, and a transformation in world view and self-identity.

Many of these participants reflected on the structural connections between women's reproductive role and greater contribution to unpaid work and low representation in senior positions (Elson, 2009). These participants recognised that pregnancy, childcare and domestic responsibilities are 'problematic to those seeking equality' because women enter and compete in the work force on an unequal footing. They embraced paid parental leave and differential treatment to acknowledge and value women's reproductive roles and viewed that organisations should be more lenient 'with time off to be with children'. However, they also understood that women's reproductive roles and the gendered division of housework create specific obstacles 
to women's advancement, while simultaneously enhancing men's career prospects. They questioned tacit knowledge surrounding long-hours work cultures, and interpreted taking parental leave within this context as a barrier to women's careers. They appreciated that by taking responsibility to 'balance their work and family commitments', women free up men's time to engage in career enhancing activities, such as facilitating 'relationship building' and 'after hours networking'. This analysis of the way women's family responsibilities reproduce unequal employment outcomes is best captured by Amanda:

Most domestic unpaid work is done by women while men do most paid work. Most [working] women ... still need to cook, clean the house, look after the children and go shopping. Therefore, women ... need to balance ... their family and their career. Most men leaders ... do not need to consider ... domestic work ... and can spend more time in the workplace ... setting up networks and building relationships.

While maintaining a strong commitment to equality in terms of 'pay, status and the treatment of women', Jenny questioned her prior tacit assumptions regarding her 'male informed' standard of career success. In the process, she starts to experience a shift in her selfidentity:

Today I realised that [my focus on climbing the corporate ladder] may be reinforcing [social norms that] I am supposedly opposed to...I am now realising that [success] is more than [this]. I have other aspirations after university...but maybe [success] is about life fulfilment and happiness, not just in terms of money.

Others focused their attention on women's concentration in low paying and precarious employment. They made deep connections between global and local gendered labour market segmentation, the gendering of low paid work, and the feminization of poverty (Elias, 2009). These participants conceded that merit-based employment decisions 'might help some women'. However, they appreciated that achieving substantive equality will require addressing the political and economic arrangements that create and sustain gendered labour market segmentation, marginalization, and low wage structures. Rebecca reflects on this structural complexity when she considers women's marginalization within the global economy: 
Although [work place policies, like EEO] help some [the] ... large contingent of women in ... casual [or] part time work miss out.... [What about] outsourcing work to another country ... that is willing to do the same work cheaper... The scary thing about it is, that [equality policies] that are supposed to be protecting us are, in many ways, preventing equality and in the case of [outsourcing] oblivious to the actual needs of all employees... It is disheartening to know that even though we are making progress, it is very little and very slow progress, so there is no shift in battling equality... The structure that is currently in place is definitely hindering any change and without a change in structure, there really is no hope at all.

As part of this deeper structural critique, some called for the re-evaluation of both the wage rate and the social importance of the work typically performed by women. Betsy does so by reflecting on women who clean for a living:

So what if a woman wants to clean motels for the rest of her life? I know some that do, and they couldn't be happier. The hours suit, it's close to home, they enjoy the camaraderie and creating clean spaces. But [the low wages] and [short hours] won't save these women and their children from poverty... Who will clean the motel room, the office toilets and the cafeterias if all of the cleaning ladies ... decided to enrol in medical school? Why don't we just pay these people an equitable wage?

In summary, these participants integrated their understanding of systemic discrimination with their sophisticated interpretations of equality that acknowledged women and men's sameness and difference. They recognised that systemic discrimination requires a systemic response (Shepard, 2012). This enabled them to de-couple equality from meritocracy and appreciate a range of interventions to address historic privileging and patriarchal power relations and the gendering effects of family arrangements, employment practices and the political economy. Thus, these participants experienced a transformation in world view and self-identity. 


\section{Discussion}

Despite considerable attention by the UN, governments, organisational leaders and scholars, gendered inequality in employment persists globally. We agree with Sipe et al., (2016) and the NCWNZ (2015) that developing a shared understanding about systemic discrimination and an appreciation for the range of interventions available are necessary prerequisites for realising gender equality. Framing equality as a threshold concept enabled an exploration of whether it is possible to do so within the context of an HRM course. As the findings show, all participants developed a sophisticated understanding of systemic discrimination and were well versed in gendered employment outcomes. Despite this, there were variations in participant comprehension about the complexity of equality and in their appreciation for the range of interventions on offer.

Land et al., (2005) argue that the differences in comprehension is partly influenced by pre-liminal variations that student's bring to the classroom; such as their prior experiences, learning styles, and approaches to study. Thus, while students might grasp specific building blocks of information, these pre-liminal variations might prevent them from integrating knowledge or appreciating the 'underlying game' that links abstract ideas together to form deeper meanings (Land et al., 2005, p 55). Because of these variations in comprehension, they suggest that threshold concepts serve to identify the 'crucial points' (p. 57) where students remain stuck or encounter troublesome knowledge and are unable to progress in their thinking. In contrast, Hawkins and Edwards (2015) argue that threshold concepts 'cannot be accessed in the abstract, but are comprehended in relation to - or possibly out of - the undergraduates own experiences and preconceptions’ (p. 33). Moreover, Herbitt and Cunliffe, (2015) argue that prior experiences might cause learners to reject deeper meanings embedded in the threshold concept. Indeed, as noted earlier, women do experience discrimination in many different ways (NCWNZ, 2015).

Like Land et al., (2005) suggest, the participants who moved to the post-liminal space did integrate their understanding of systemic discrimination and gendered employment outcomes and developed sophisticated interpretations of equality and thus perceived that the development of political, economic, social and cultural conditions would be required to support substantive equality. These participants also drew on a combination of abstract ideas presented throughout the course to reflect on their transformation in worldview and personal identity. 
The participants who remained in the liminal and pre-liminal space grasped systemic discrimination and gendered employment as specific building blocks of information. Thus, they became stuck at the point of integrating this knowledge with equality. Moreover, the pervasiveness of neo-liberal rhetoric within our own national context of New Zealand is emphasised in the way these participants held on to their agendic self-identity and in their interpretation of equality as identical treatment. Those who remained in the liminal space perceived that gender equality could be realised through merit-based employment practices that enable capable women, such as themselves, access to and advancement within current structures. Thus, their interpretation of equality and appreciation for merit-based employment policies upheld their post-feminist identity. In contrast, those who remained in the pre-liminal space particularly experienced equality as troublesome knowledge that directly challenged their agendic self-identity. Just as Herbitt and Cunliffe, (2015) suggest, to maintain their identity, these participants rejected deeper systemic issues, and instead interpreted equality measures as discrimination.

This reflexive review of student learning provided us with insight to modify the lectures to support learners to integrate their knowledge about systemic discrimination and gendered employment outcomes with equality. Specifically, we have developed a series of group-based discussion exercises that have the aim of enabling students to reflect on systemic discrimination and gendered employment outcomes in relation to their personal experiences. While it is too early to determine the effectiveness of these exercises, our active listening to these group discussions suggests that the process of sharing experiences is enabling some to integrate abstract ideas and to form deeper meanings.

\section{Conclusion}

In this article we have examined how management students who are enrolled in a specific HRM course and who have analysed systemic discrimination, interpret equality and make sense of and appreciate the interventions designed to redress gendered employment outcomes. By delving into learners' comprehension, we can conclude that it is possible to develop a shared understanding of systemic discrimination and gendered employment outcomes. However, we can also conclude that interpretations of equality and appreciation for the interventions is influenced by student ability to integrate abstract ideas and by the extent to which the complexity of equality transforms, upholds or challenges self-identity. Thus, our 
findings reveal that it is also necessary to support students to integrate their understanding of systemic discrimination and gendered employment outcomes with their interpretation of equality and appreciation for the range of interventions on offer. Whether extending discussions on systemic discrimination and the possible interventions at multiple stages of business school curriculum, or by giving students multiple opportunities for reflection would result in a deeper analysis for more students, remains the scope of further research.

Although delivering insights, the study is not without limitations. In particular, the New Zealand business education context, while recognised as having similarities to Australia, United Kingdom and United States in terms of curriculum and quality, does have a distinct classroom culture, which may impact on the nature of student reflections. In addition, the unique socio-cultural context and the neo-liberal political economy that surround discussions of equality within New Zealand was seemingly entrenched in many of our participant's agendic self-identity. Furthermore, while the data is rich, the sample size of 38 participants, including 35 women, limits the broad generalisability of the findings. Moreover, given the limited demographic details of the participants, it was not possible to develop a deeper, intersectional analysis of the reflexive journals. Similarly, because we did not gather data on prior experiences, we were unable determine whether, or to what extent pre-liminal variations shaped participant comprehension of equality as a threshold concept.

For the wider research community, this research supports a continued examination of equality as a theoretical construct. Far from being rendered irrelevant, this study highlights that unequal outcomes are an ongoing concern in the contemporary workplace, and that understanding equality as part of the discursive development of the wider DM and inclusion scholarship and as a foundation theoretical construct, remains important to those of us interested in exploring justice and injustice in the workplace. 


\section{References}

Annesley, C., Engeli, I., and Gains, F. (2015), The profile of gender equality issue attention in Western Europe, European Journal of Political Research, Vol. 54 No. 3, pp. 525542.

Arat, Z. (2015), Feminisms, Women's Rights, and the UN: Would Achieving Gender Equality Empower Women? American Political Science Review, Vol. 109 No.4, pp. 674-689.

Bacik, and Drew. (2006), Struggling with juggling: Gender and work/life balance in the legal professions. Women's Studies International Forum, Vol. 29 No. 2, pp. 136-146.

Beck, D., \& Davis, E. (2005). EEO in senior management: Women executives in Westpac. Asia Pacific Journal of Human Resources, Vol. 43 No. 2, pp. 273-288.

Bradley, Thomas P., Burch, Gerald F., \& Burch, Jana J. (2015). Increasing Knowledge by Leaps and Bounds: Using Experiential Learning to Address Threshold Concepts. Organization Management Journal, Vol. 12 No. 2, pp. 87-101.

Braun, V., \& Clarke, V. (2006). Using thematic analysis in psychology. Qualitative Research in Psychology, Vol. 3 No.2, pp. 77.

Convention on the Elimination of All Forms of Discrimination against Women, United Nations Women, Available from http://www.un.org/womenwatch/daw/cedaw/cedaw.htm

Davies, S. G., McGregor, J., Pringle, J., \& Giddings, L. (2017), Rationalizing pay inequity: women engineers, pervasive patriarchy and the neoliberal chimera. Journal of Gender Studies, Online: DOI:10.1080/09589236.2017.1284048.

Elias, J. (2007), Women workers and labour standards: The problem of 'human rights', Review of International Studies, Vol. 33 No.1, pp. 45-57.

Elson, D. (2009), Gender equality and economic growth in the World Bank World Development Report 2006, Feminist Economics, Vol. 15 No.3, pp. 35-59.

Facio, A., and Morgan, M. I. (2009), Equity or Equality for women? Understanding CEDAW's Equality Principles, Alabama Law Review, Vol. 60 No. 5, pp. 1133-1170. 
Fotaki, M., \& Prasad, A. (2015), Questioning neoliberal capitalism and economic inequality in business schools. Academy of Management Learning \& Education, Vol. 14, No. 4, pp. 556-575.

Fetterolf, J. and Eagly, A. (2011), Do Young Women Expect Gender Equality in Their Future Lives? An Answer From a Possible Selves, Sex Roles, Vol. 65 No.1, pp. 8393.

Finney, T. G., Finney, R. Z., and Parry, R. O. (2014). EEO/AA and "doing good": An exploratory study, International Journal of Law and Management, Vol. 56 No. 6, pp. 443.

Gill, R., \& Scharff, C. (2011), New femininities: Post \feminism, neoliberalism, and subjectivity. New York; Houndmills, Basingstoke, Hampshire: Palgrave Macmillan.

Hawkins, B., and Edwards, G. (2015), Managing the monsters of doubt: Liminality, threshold concepts and leadership learning, Management Learning, Vol. 46 No. 1, pp. 24-43.

Hibbert, P., \& Cunliffe, A. (2015). Responsible Management: Engaging Moral Reflexive Practice Through Threshold Concepts. Journal of Business Ethics, 127(1), 177-188.

Humphries, M., and Grice, S. (1995), Equal employment opportunity and the management of diversity: A global discourse of assimilation?, Journal of Organizational Change Management, Vol. 8 No. 5, pp.17-32

ILO. (2016). Women at work. Retrieved from http://www.ilo.org/wcmsp5/groups/public/--dgreports/---dcomm/---publ/documents/publication/wcms_457317.pdf.

Jolles, M. (2012), Going rogue: Postfeminism and the privilege of breaking rules, Feminist Formations, Vol. 24 No.3, pp. 43-61.

Knights, D. and Omanović, V. (2016), (Mis)managing diversity: Exploring the dangers of diversity management orthodoxy, Equality, Diversity and Inclusion: An International Journal, Vol. 35 No.1, pp. 5-16.

Land, R., Cousin, G., Meyer, J. H., and Davies, P. (2005), Threshold concepts and troublesome knowledge (3): implications for course design and evaluation. Improving student learning diversity and inclusivity, Vol. 4, pp. 53-64. 
McDonald, E. (2014), Feminist legal theory in Aotearoa New Zealand: The impact of international critical work on local criminal law reform. Women's Studies Journal, Vol. 282 No.1, pp. 68-87.

McPherson, M. (2008). Diversity and Equality: Evidence of positive business outcomes and how to achieve them: A review of the Literature, Equal Employment Opportunities Trust; Auckland: New Zealand.

McRobbie, Angela (2004), Post-feminism and popular culture. Feminist Media Studies. Vol. 4 No. 3, pp. 255-264.

Messing, K., Lippel, K., Demers, D., and Mergler, D. (2000), Equality and difference in the workplace: Physical job demands, occupational illnesses, and sex differences. NWSA Journal, Vol. 12 No. 3, pp. 21-49.

Meyer, J., and Land, R. (2003), Threshold concepts and troublesome knowledge: Linkages to ways of thinking and practising within the disciplines, Edinburgh: University of Edinburgh, pp. 412-424

Meyer, Jan H. F., and Land, Ray. (2005), Threshold Concepts and Troublesome Knowledge (2): Epistemological Considerations and a Conceptual Framework for Teaching and Learning, Higher Education: The International Journal of Higher Education and Educational Planning, Vol. 49 No. 3, pp. 373-388.

Ministry of Business, Innovation, and Employment. (2015), International Labour Conventions Ratified by New Zealand. New Zealand Government, Wellington. http://www.mbie.govt.nz/info-services/employment-skills/internationalservices/document-image-library/international-labour-conventions-ratified-by-nz.pdf

Ministry for Women. (2016), Women on Private Sector Boards: A review of initiatives in selected countries. Wellington, New Zealand: Ministry for Women.

Mintrom, M., and True, J. (2004). Framework for the Future Equal Employment Opportunities in New Zealand: Report Produced for the Equal Employment Opportunities Unit of the Human Rights Commission, as Part of the Equal Employments Opportunities Framework. Wellington, NZ: The Human Rights Commission.

National Council of Women of New Zealand (NCWNZ, 2015), Enabling women's potential: The social, economic and ethical imperative. A White Paper from the Te Kaunihera Wahine O Aotearoa. 
O’Connell, T. S., \& Dyment, J. E. (2011). The case of reflective journals: Is the jury still out? Reflective Practice: International and Multidisciplinary Perspectives, Vol. 12 No. 1, pp. 47-59.

Oswick, C., and Noon, M. (2014), Discourses of Diversity, Equality and Inclusion: Trenchant Formulations or Transient Fashions? British Journal of Management, Vol. 25 No. 1, pp. 23-39.

Parker, J., Nemani, M., Arrowsmith, J., and Bhowmick, S. (2012), Contemporary Collective Regulation and Working Women in New Zealand, Journal of Industrial Relations, Vol. 54 No. 2, pp. 221-237.

Perriton, L. 2007. Really useful knowledge? Critical Management Education in the UK and the US. Scandinavian Journal of Management, 23(1), 66-83.

Phipps, Alison. (2014), Politics of the body: Gender in a neoliberal and neoconservative age. Oxford, GBR: Wiley.

Pringle, J. K., \& Strachan, G. (2015). Duelling Dualisms. In Bendl, R., Bleijenbergh, I., Henttonen, E., \& Mills, A. J. (Eds.). The Oxford handbook of diversity in organizations. Oxford University Press, pp. 39-61

Ryan, I., Ravenswood, K., \& Pringle, J. K. (2014), Equality and diversity in Aotearoa New Zealand. In Klarsfeld, A., Booysen, L. A., Ng, E., Roper, I., \& Tatli, A. (Eds.), 9.78 E+ 12: Country Perspectives on Diversity and Equal Treatment. Edward Elgar Publishing.pp. 175-194

Sharma, S., and Sharma, M. (2012), Gender equality in the workplace: The perceptive reality, Social Sciences Directory, Vol. 1 No.1.

Sipe, S., Larson, L., McKay, B. A., and Moss, J. (2016), Taking off the Blinders: A Comparative Study of University Students' Changing Perceptions of Gender Discrimination in the Workplace From 2006 to 2013, Academy Of Management Learning and Education, Vol 15 No.2, pp. 232-249.

Stake, Jayne E. (2007), Predictors of change in feminist activism through women's and gender studies. Sex Roles Vol. 57, No.1-2, pp. 43-54. 
Statistics New Zealand (2015), Women at work: 1991-2013, Wellington, New Zealand, Available from www.stats.govt.nz

Statistics New Zealand (2016), Household Labour Force Survey, Wellington New Zealand, Available from www.stats.govt.nz

Staines, G. (1980), Spillover Versus Compensation: A Review of the Literature on the Relationship Between Work and Nonwork, Human Relations, Vol. 33 No. 2, pp.111.

Terjesen, S., and Sealy, R. (2016), Board gender quotas: Exploring ethical tensions from a multi-theoretical perspective, Business Ethics Quarterly, Vol. 26 No. 1, pp. 23-65.

Wagner, Anne. (2014), Re-imagining the (un)familiar: feminist pedagogy in rural spaces, Gender and Education Vol. 26, No. 5, pp. 553-567.

Wright, A., and Gilmore, A. (2012), Threshold Concepts and Conceptions, Journal of Management Education, Vol. 36 No.5, pp. 614-635.

Acts and Legislation

Education Act, 1989 